\title{
Berberine from Argemone mexicana $L$ exhibits a broadspectrum antibacterial activity
}

\author{
Nilesh V. More ${ }^{1,2}$, Kiran R. Kharat ${ }^{3}$ and Arun S. Kharat ${ }^{1,4 凶}$ \\ 'Department of Biotechnology, Dr. Babasaheb Ambedkar Marathwada University, Subcampus, Osmanabad 413501, Maharashtra, India; 2Depart- \\ ment of Biotechnology, College of Computer Science and Information Technology, Latur 413512, Maharashtra, India; ${ }^{3}$ Center for Advanced Life \\ Sciences, Deogiri College, Aurangabad, 431001, India; ${ }^{4}$ School of Life Sciences, Jawaharlal Nehru University, New Delhi 110 067, India
}

The Argemone mexicana L, commonly found on desolate land in the Marathwada region of Maharashtra state, India, has been used for treating oral cavity infections. We sought to investigate the antimicrobial potential of A. mexicana L. In this study, cold aqueous and methanolic extracts were prepared from the A. mexicana $\mathrm{L}$ leaves. These extracts were tested for their antibacterial activities against selected bacterial isolates. The antibacterial activity and MICs were tested using the agar well diffusion method and broth dilution method, respectively. The cold aqueous and methanolic extracts of A. mexicana $L$ leaves inhibited growth of clinical isolates of Staphylococcus aureus, Bacillus cereus, Escherichia coli and Pseudomonas aeruginosa. The antibacterial potentiality of $A$. mexicana $\mathrm{L}$ extracts was compared with Streptomycin - the reference antibiotic used in this study. The active ingredient of antibacterial potentiality within the A. mexicana $\mathrm{L}$ extract was purified and characterized by TLC, HPLC and NMR analysis. Structural elucidation of Berberine and its bioactivity both, from the A. mexicana $\mathrm{L}$ and commercial preparation, is investigated.

Key words: antibacterial potentiality, Argemone mexicana, aqueous, methanolic extract, HPLC, NMR and phytochemical analysis

Received: 11 June, 2017; revised: 08 November, 2017; accepted: 09 November, 2017; available on-line: 13 December, 2017

e-mail: arunkharat2007@gmail.com

Abbreviations: A. mexicana $\mathrm{L}$, Argemone mexicana $\mathrm{L}$

\section{INTRODUCTION}

About $80 \%$ of the population in developing countries relies for its primary health care needs on traditional and/or alternative medicine which is based on medicinal plants (Newman \& Cragg, 2007). It is estimated that about $87 \%$ of all categorized human diseases, including microbial infections, cancer, metabolic disorders and immunological disorders, have been treated with natural products and alternative medicines (Uddin et al., 2011). Commonly used medicinal plants and vegetables not only possess the essential nutrients but are also reported to contain secondary metabolites, such as alkaloids, flavonoids, glycosides, terpenoids and phenolics (Cai et al., 2004; Abdelwahab et al., 2010). Currently, there is a great number of antibiotics available to treat microbial infections, however, it is well documented that many infectious agents have attained resistance to several of these antibiotics (Roux et al., 2012; Kapoor et al., 2017). This has posed a great difficulty in treating microbial infections. An introduction of fixed drug combinations could override this difficulty in a few cases (McGettigan et al.,
2015). However, for many microbial infections, in particular bacterial ones, even a fixed drug combination approach has been also found to be ineffective. For over one and a half decades no new antibiotics with the ability to escape the microbial drug resistance phenomenon have been added (Sorg et al., 2016). The Argemone mexicana L. (Papaveraceae), commonly known as prickly poppy, has been used as a medicinal plant in Mexico, Nigeria and tropical America (Rosas-Pinon et al., 2012; Gupta et al., 2015). It is used to treat different ailments, given its antimicrobial, antiparasitic, antimalarial, pesticide, cytotoxic and neurological properties (Graz et al., 2010; Rubio-Pina \& Vazquez-Flota, 2013). Fresh yellow, milky seed extract containing protein-dissolving substances is effective in the treatment of warts, cold sores, skin diseases, itches and jaundice (Chopra et al., 1986). Previous studies by (Bhattacharjee et al., 2006; Singh et al., 2009; Osho \& Afetunji, 2010; Alagesaboopati \& Kalaiselvi, 2012 and Sahu et al., 2012) reported antibacterial activity in root, stem, leaves, seed and essential oil extracts of $A$. mexicana L. In-vitro antibacterial activity of the stem of $A$. mexicana $\mathrm{L}$ and wild medicinal plants were also evaluated by (Rahman et al., 2009 and Saranya et al., 2012). Recently, antifungal (Doss et al., 2012 and More \& Kharat, 2016) and anticancer potentiality of $A$. mexicana L has been reported (More \& Kharat, 2016). Despite the number of antibacterial potentiality reports on $A$. mexicana $\mathrm{L}$, it is unclear which of the phytochemicals are responsible for this potentiality. In this study, we aimed to explore the existence of antibacterial potential for $A$. mexicana against pathogenic bacteria. The second objective of this study included isolation, purification and characterization of the phytochemical conferring antibacterial potential to $A$. mexicana $\mathrm{L}$. Cold aqueous and methanolic extracts prepared from $A$. mexicana leaves were processed for determination of antibacterial potential against pathogenic isolates: Gram positive, i.e. Staphylococcus aureus and Bacillus cereus, and Gram negative, i.e. Escherichia coli and Pseudomonas aeruginosa. The results obtained on the antibacterial potential and analytical studies on the characterization of the active ingredient and functional confirmation on antibacterial potentiality are discussed.

\section{MATERIALS AND METHODS}

Bacterial culture maintenance. The bacteria used in this study included Gram positive bacteria: Staphylococcus aureus $\left(\mathrm{Amox}^{\mathrm{R}} \& \mathrm{Amp}^{\mathrm{R}}\right.$ ) and Bacillus cereus, and Gram negative bacteria: Escherichia coli $\left(\mathrm{Amp}^{\mathrm{R}} \& \mathrm{Chl}^{\mathrm{R}}\right)$ and Pseudomonas aeruginosa $\left(\mathrm{Pen}^{\mathrm{R}} \& \mathrm{Amp}^{\mathrm{R}}\right)$. They were maintained on nutrient agar (NA) slants at $4^{\circ} \mathrm{C}$ (HiMedia India). The bioassay of bacterial suspension was obtained by inocula- 
tion using nutrient broth for $24 \mathrm{~h}$, followed by ten-fold serial dilution in PBS $\mathrm{pH} 7.2$ to obtain $\mathrm{CFU} / \mathrm{mL}=10^{6}$.

The A. mexicana plantparts. The plant material was verified and authenticated with the Herbarium Center, Department of Botany, Dr. Babasaheb Ambedkar Marathwada University, Aurangabad, India. It was confirmed as A. mexicana L., a member of the Papaveraceae family and is commonly referred to as Swarnakshiri, Bilayat and Pivla Dhotra. The allotted accession number is 0609. Leaves of $A$. mexicana were collected and rinsed with sterile double distilled water, disinfected with $70 \%$ alcohol and then dried on paper towel at room temperature. After drying, the plant materials were ground in a laboratory grinding machine.

Methanolic extracts. The methanolic extracts were prepared as described in More \& Kharat (2016). Briefly, in a tightly sealed container at room temperature, 50 $g$ of the grounded plant material were extracted with $150 \mathrm{~mL}$ of methanol. The extract was protected from light and kept overnight on a rotary shaker (Remi, Elektrotechnik, Ltd., Mumbai, India). The extract was filtered through a five layered sterile muslin cloth. The procedure was repeated three times to obtain clear and colorless filtrate. The methanol from the filtrate was removed by rotary evaporation (Rotary Evaporator, EJER tech, Hangzhou, Zhejiang, China). Extract was stored at $16^{\circ} \mathrm{C}$ overnight, and subsequently freeze-dried at $-60^{\circ} \mathrm{C}$ in a $20 \mathrm{~mL}$ vacuum for $24 \mathrm{~h}$. The extract was then sterilized with UV and stored in an airtight container at $4^{\circ} \mathrm{C}$ until further use.

Aqueous extracts. Exactly $50 \mathrm{~g}$ of grounded plant material were extracted with $150 \mathrm{~mL}$ sterile double distilled water for $24 \mathrm{~h}$, as in the case of methanol. The mixture was filtered through a sterile five-layered muslin cloth and centrifuged at $5000 \mathrm{rpm}$, and the supernatant was concentrated with the rotary evaporator (EJER tech, Hangzhou, Zhejiang, China). The concentrated extract, free from liquid, was then UV sterilized and stored at $4^{\circ} \mathrm{C}$ until further use. At the time of experiment, the dry mass was resuspended to achieve $2 \mathrm{mg} / \mathrm{ml}$ concentration.

Antibacterial potentiality test. The antibacterial potentiality of $A$. mexicana was tested with minor modifications byan agar well diffusion method described by (Boyanova et al., 2005). An inoculum of $10^{6} \mathrm{CFU} / \mathrm{mL}$ was adjusted in molten Muller Hinton agar and poured into pre-sterilized petri-plates. Upon solidification, wells were punched with a sterile cork borer (Scientific laboratory, New Delhi, India). Each well was filled with $40 \mu \mathrm{g}$ of the extract $(20 \mu \mathrm{L})$. As an antibacterial standard, streptomycin $(40 \mu \mathrm{g})$ was used for comparison. Plates were then incubated at $37^{\circ} \mathrm{C}$ for $24 \mathrm{~h}$ for the detection of inhibitory zones. The experiments were repeated three times; the average and standard deviations (S.D.) were then calculated. Antibacterial activity was evaluated by measuring the diameter of growth inhibition zone around the well.

Phytochemical analysis of the A. mexicana leaf extracts. Qualitative and quantitative estimates for various phytochemicals of $A$. mexicana extracts were performed. Existence of phytochemicals was confirmed by performing various biochemical tests, namely the Molish's test for carbohydrates, ninhydrin test for proteins, $\mathrm{FeCl}_{3}$ test for tannins, foam test for saponins, fluorescence test for coumarins, Fehling's test for glycosides, Shinoda test for flavonoids, Liebermann Burchard test for steroids and terpenoids, as well as Dragendorff test for alkaloids, as described in Rajpal (2005). For the estimation of phytochemicals, $1 \mathrm{~g}$ of powder dissolved in $20 \mathrm{~mL}$ of water was incubated in a water bath incubator at $65^{\circ} \mathrm{C}$ for
$15 \mathrm{~min}$ and filtered through five layered sterile muslin cloth. The filtrate obtained was used in the analysis of carbohydrates, saponins, proteins and tannins.

Minimum inhibitory concentration (MIC) of the leaf methanolic extracts of $\boldsymbol{A}$. mexicana. The MIC was calculated as the lowest concentration that inhibits growth of the tested organism. Minimum inhibitory concentration (MIC) was determined by agar well diffusion method (Boyanova et al., 2005) and standard broth dilution techniques (Washington \& Sutter 1980). On each Müller Hinton agar plates, $8 \mathrm{~mm}$ wells were punched with a sterile cork borer. Sample extracts were prepared at a concentration of $10 \mathrm{mg} / \mathrm{ml}, 20 \mathrm{mg} / \mathrm{ml}, 30 \mathrm{mg} / \mathrm{ml}$ and upto $100 \mathrm{mg} / \mathrm{ml}$. The plates were then incubated at $37^{\circ} \mathrm{C}$ for 18 to $24 \mathrm{~h}$. The inhibitory zone which appeared around the well was recorded. In the case of broth dilution, bacteria were inoculated in Müller Hinton broth supplemented with $200 \mathrm{mg} / \mathrm{ml}, 400 \mathrm{mg} / \mathrm{ml}, 800 \mathrm{mg} /$ $\mathrm{ml}$, and $1600 \mathrm{mg} / \mathrm{ml}$ of the leaf methanolic extracts of A. mexicana. Tubes were incubated at $37^{\circ} \mathrm{C}$ for $24 \mathrm{~h}$, the lowest concentration inhibiting bacterial growth was expressed as MIC in $\mathrm{mg} / \mathrm{ml}$.

Thin layer chromatography for crude extracts and berberine chloride. The methanolic extracts of $A$. mexicana leaves and berberine (Sigma-Aldrich) were prepared by dissolving in methanol $(\mathrm{mg} / \mathrm{ml})$ and collected in two test tubes. The TLC plates, $15 \mathrm{~cm} \times 10 \mathrm{~cm} \times 0.3 \mathrm{~cm}$ (length $\times$ width $\times$ thickness) were overlaid with a slurry of silica gel with calcium sulphate as the binder. An aliquot of $20 \mu \mathrm{l}$ sample was loaded onto the thin layer chromatography plate and put in a buffer tank containing Hexane: chloroform: methanol $(4: 4: 2, \mathrm{~V} / \mathrm{V} / \mathrm{V})$; theresulting chromatogram bands were visualized by iodine vaporization.

Column chromatography conditions. A 1.5 $\mathrm{cm} \times 30 \mathrm{~cm}$ (diameter $\times$ height) column was packed with $15 \mathrm{~g}$ of silica powder made in the $\mathrm{n}$-Hexane solvent. The extract was then loaded onto the top of the column and saturated for $3 \mathrm{~h}$. The elution was done by using 20 different mobile phases (Table 3) shifting from non-polar to polar in an increasing order. These fractions, along with the berberine, were then used for the TLC analysis. The $R_{f}$ values for each fraction were recorded and compared with berberine. Fraction 12 indicated similar $R_{f}$ value with berberine. Hereafter, fraction 12 was utilized for further ultra-purification with HPLC and deciphering structure with $1 \mathrm{H}$ NMR.

High Performance Liquid Chromatography conditions. Analysis was performed using a high performance liquid chromatography system (Shimadzu's Prominence HPLC class LC-20AD, Japan), with a Prominence Pump, High precision dual plunger design and forced check valve design for excellent solvent delivery control (Schewenninger et al., 2008). A reverse-phase C18 column (length $250 \mathrm{~mm}$, dia $-4.6 \mathrm{~mm}$, particle size $5 \mu \mathrm{m}$, pore size $100 \AA$, Material: Silica, Spherical Fully Porous Ultrapure) was used (Syncronis, ThermoFisher Scientific, Inc, USA). All analyses were performed at room temperature with a mobile phase of methanol and acetonitrile (60:40), an injection volume of $10 \mu \mathrm{l}$, and a flow rate of $1.0 \mathrm{~mL} / \mathrm{min}$. The column effluent was monitored at $214 \mathrm{~nm}$ with an L-2400 series multi-wavelength UV Detector. Fractions were collected for further analysis of antibacterial activity and structure determination on the basis of their RT.

NMR spectroscopy conditions. NMR studies were conducted to predict the structure of the chemical compound present in the HPLC purified fraction. The analysis was performed with the Advance - III $400 \mathrm{MHz}$ 

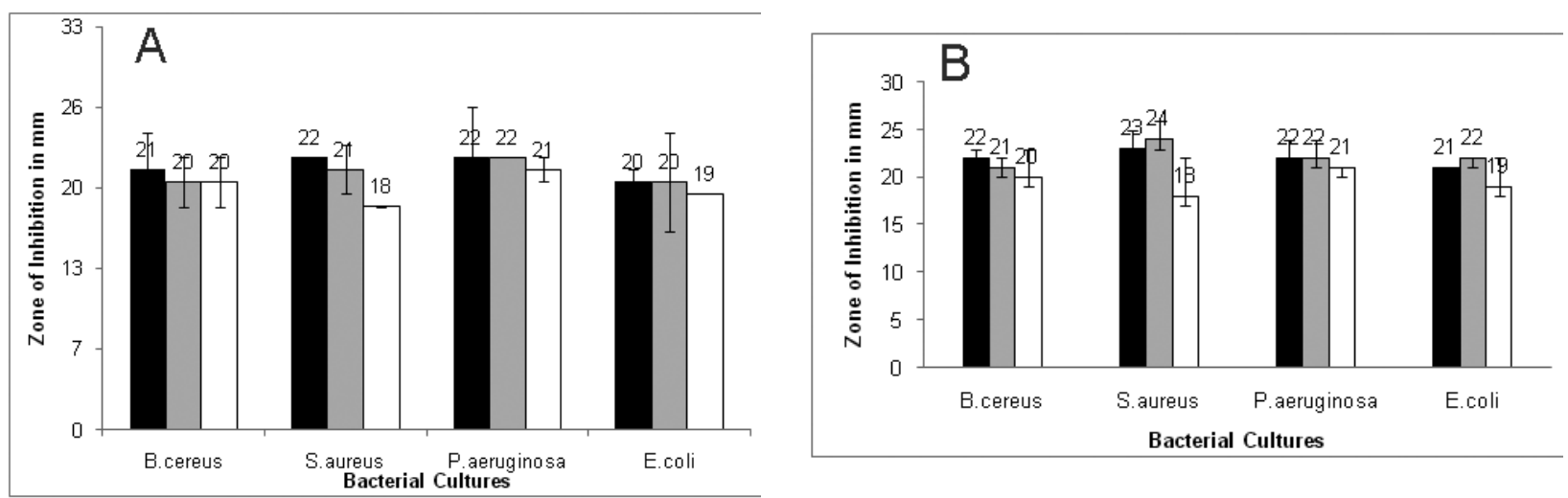

Figure 1A. Antibacterial activity of methanolic and aqueous extract against four tested bacteria:

The X-axis shows clinical isolates used in this study; Y-axis shows zone of inhibition represented by bars: (1) B. cereus; (2) S. aureus; (3) $P$. aeruginosa; and (4) E. coli. Antibacterial activity within methanolic extracts of leaves (black bars), aqueous (gray bars) for $A$. mexicana extracts, while empty bars denote antibacterial activity of streptomycin. Error bars shown on each histogram indicate standard deviation. Figure 1B. Functional demonstration of antibacterial potency of purified berberine:

Zone of inhibition in $\mathrm{mm}$ against different Gram positive and Gram negative bacteria, standard berberine chloride, HPLC purified fraction and streptomycin. The black bars indicate berberine, gray bars indicate HPLC peak 2, while the empty bars denote streptomycin mediated antibacterial activity

Table 1. Determination of MIC for the A. mexicana methanolic and aqueous extracts.

\begin{tabular}{|c|c|c|c|c|c|c|c|c|c|}
\hline \multirow{3}{*}{$\begin{array}{l}\text { Sr. } \\
\text { No }\end{array}$} & \multirow{3}{*}{$\begin{array}{l}\text { extract } \\
\text { in } \mu \mathrm{g} / \text { well }\end{array}$} & \multicolumn{8}{|c|}{ Zone of Inhibition (in $\mathrm{mm}$ ) } \\
\hline & & \multicolumn{2}{|c|}{ B. cereus } & \multicolumn{2}{|c|}{ S. aureus } & \multicolumn{2}{|c|}{ P. aeruginosa } & \multicolumn{2}{|c|}{ E. coli } \\
\hline & & Methanolic & Aqueous & Methanolic & Aqueous & Methanolic & Aqueous & Methanolic & Aqueous \\
\hline 01 & 200 & $10+/-1$ & $10+/-1$ & $9+/-2$ & $10+/-1$ & $10+/-2$ & $10+/-1$ & $9+/-1$ & $11+/-1$ \\
\hline 02 & 400 & $15+/-2$ & $16+/-1$ & $14+/-1$ & $13+/-2$ & $16+/-1$ & $17+/-2$ & $13+/-1$ & $13+/-1$ \\
\hline 03 & 600 & $17+/-1$ & $20+/-2$ & $17+/-1$ & $17+/-1$ & $18+/-1$ & $18+/-1$ & $16+/-1$ & $16+/-1$ \\
\hline 04 & 800 & $21+/-1$ & $20+/-1$ & $22+/-1$ & $21+/-1$ & $22+/-1$ & $22+/-1$ & $20+/-1$ & $20+/-1$ \\
\hline 05 & 1000 & $21+/-1$ & $20+/-1$ & $22+/-1$ & $21+/-1$ & $22+/-1$ & $22+/-1$ & $20+/-1$ & $20+/-1$ \\
\hline
\end{tabular}

Note: Values for inhibitory zones were recorded from at least three experiments, +/- denotes Standard deviation.

Table 2. Detection of phytochemicals from the methanolic extracts of $A$. mexicana leaves

\begin{tabular}{|c|c|c|c|}
\hline Phytochemical compounds & Leaf Extract & Phytochemical compounds & Leaf Extract \\
\hline Carbohydrate & Present & Glycoside & Present \\
\hline Saponin & Absent & Flavonoid & Present \\
\hline Protein & Absent & Phytosterol & Absent \\
\hline Split amino acids & Absent & Phenolics & Absent \\
\hline Tannin & Present & Alkaloid & Present \\
\hline Coumarins & Present & & \\
\hline
\end{tabular}

Fourier Transform Digital NMR Spectrometer (Bruker Biospin, Switzerland) $1 \mathrm{H}$ in DMSO-D6. 1H NMR spectra of HPLC Peak 2 and standard berberine chloride were recorded. Chemical shifts were recorded as a delta value. For graphical analysis, amestrenova software was used. The software enabled identification of the compound present in the HPLC purified fraction.

Antibacterial activity of the HPLC purified fraction. The antibacterial potentialityidentified in $A$. mexicanaleaf extract was confirmed with agar well diffusion assay as described above. The HPLC purified extract, along with berberine and a comparison standard antibi- otic streptomycin, were used for the antibacterial assay. The inhibitory zones against test organisms were analyzed.

\section{RESULTS}

\section{Antibacterial potential of $A$. mexicana}

One of the aims of this study was to address whether or not $A$. mexicana has antibacterial potentiality against clinical isolates. The methanolic and cold aqueous ex- 
Table 3. Mobile Phase used for column chromatography

\begin{tabular}{|c|c|c|c|}
\hline Sr.No. & $\begin{array}{l}\text { Frac- } \\
\text { tions }\end{array}$ & Mobile Phase & $\begin{array}{l}\text { Volume } \\
\text { in } \mathrm{ml}\end{array}$ \\
\hline 1 & 1 & n-Hexane:Chloroform(8:2) & $10 \mathrm{ml}$ \\
\hline 2 & 2 & n-Hexane:Chloroform(6:4) & $10 \mathrm{ml}$ \\
\hline 3 & 3 & n-Hexane:Chloroform(3:7) & $10 \mathrm{ml}$ \\
\hline 4 & 4 & n-Hexane:Chloroform(1:9) & $10 \mathrm{ml}$ \\
\hline 5 & 5 & Chloroform:Ethyl Acetate(7:3) & $10 \mathrm{ml}$ \\
\hline 6 & 6 & Chloroform:Ethyl Acetate(5:5) & $10 \mathrm{ml}$ \\
\hline 7 & 7 & Chloroform:Ethyl Acetate(3:7) & $10 \mathrm{ml}$ \\
\hline 8 & 8 & Ethyl Acetate:Acetone(6:4) & $10 \mathrm{ml}$ \\
\hline 9 & 9 & Ethyl Acetate:Acetone(5:5) & $10 \mathrm{ml}$ \\
\hline 10 & 10 & Ethyl Acetate:Acetone(4:6) & $10 \mathrm{ml}$ \\
\hline 11 & 11 & Acetone:Methanol(9:1) & $10 \mathrm{ml}$ \\
\hline 12 & 12 & Acetone:Methanol(6:4) & $10 \mathrm{ml}$ \\
\hline 13 & 13 & Acetone:Methanol(5:5) & $10 \mathrm{ml}$ \\
\hline 14 & 14 & Acetone:Methanol(4:6) & $10 \mathrm{ml}$ \\
\hline 15 & 15 & Methanol:Water(8:2) & $10 \mathrm{ml}$ \\
\hline 16 & 16 & Methanol:Water(6:4) & $10 \mathrm{ml}$ \\
\hline 17 & 17 & Chloroform:Methanol(9:1) & $10 \mathrm{ml}$ \\
\hline 18 & 18 & Chloroform:Methanol(6:4) & $10 \mathrm{ml}$ \\
\hline 19 & 19 & Chloroform:Methanol(5:5) & $10 \mathrm{ml}$ \\
\hline 20 & 20 & Chloroform:Methanol(2:8) & $10 \mathrm{ml}$ \\
\hline 21 & 21 & Ethanol & $10 \mathrm{ml}$ \\
\hline 22 & 22 & Methanol & $10 \mathrm{ml}$ \\
\hline 23 & 23 & Water & $10 \mathrm{ml}$ \\
\hline
\end{tabular}

tracts prepared from the leaves of $A$. mexicana, along with streptomycin, were inoculated into wells punched in pre-seeded agar plates, as described for the agar well diffusion assay (Boyanova et al., 2005; Singh et al., 2009). After incubation at $37^{\circ} \mathrm{C}$ for $24 \mathrm{~h}$, the zone of inhibition around the well was measured and recorded as the measure of antibacterial activity. Results depicted in
Fig. 1 show that the $A$. mexicana leaf extract, methanolic (black bar) and cold aqueous (grey bar), exhibit significant antibacterial activity. The inhibitory zones obtained for methanolic and aqueous leaf extracts were found to be similar to streptomycin (empty bars), a comparison standard used in this study. These observations suggest that the $A$. mexicana leaf contains an antibacterial component of potentialilty comparable to that of streptomycin.

\section{Determination of MIC}

The A. mexicana extracts, at concentrations of $200 \mu \mathrm{g}$ /well and upto $1000 \mu \mathrm{g} /$ well, were used for the antimicrobial potential determination. The MIC concentration was determined with the agar well diffusion assay by measuring the zone of inhibition. The MIC value for A. mexicana extracts was also determined by the broth dilution method (Washington \& Sutter 1980). The inhibitory zones for agar well diffusion assay were measured (see Table 1). In the case of the broth dilution assay, bacterial growth was measured after $24 \mathrm{~h}$ incubation. Bacterial growth was found to decline with increasing concentrations of the extract. As concentrations of 800 $\mathrm{mg} / \mathrm{ml}$ and above exhibited no bacterial growth, the said concentration was regarded as the MIC.

\section{Phytochemical analysis of the leaf extract}

The existence of phytochemicals in the methanolic extract of $A$. mexicana leaves was confirmed by various biochemical tests. Results shown in Table 2 suggest that the extract contained alkaloids, tannin, glycosides, carbohydrates, courmarins and flavonoids, but was found to be devoid of proteins, split amino acids and phenolics. The lack of amino acids, proteins and phenolics in the extract might have been due to the use of methanol as the solvent. The antibacterial potency observed for the extract above is likely tobe associated with the phytochemical(s) detected in the extract.

\section{Purification and characterization of the active compound with antibacterial potency}

Thin Layer Chromatography (TLC)

After identifying phytochemicals that existed in the A. mexicana leaf methanolic extract, we then sought to purify the antibacterial compound with column chromatography. About 20 fractions were collected (see Materials \& Methods) from the column and processed for TLC analysis, along with berberine chloride as the standard alkaloid. Table 3 shows various combinations of mobile phases applied for collecting fractions. Berberine is a quaternary ammonium salt from the protoberberine group of isoquinolinealkaloids. Previous studies had reported the use of berberine in China as a broad-spectrum anti-microbial medicine (Rubio-Pina \& Vazquez-Flota, 2013). The $R_{f}$ values for 20 fractions were recorded and compared with the $R_{f}$ value obtained for berberine chloride (see Table 4). Fraction 12 of the extract showed identical $R_{f}$ values with that of berberine chloride, enhancing likelihood of the existence of berberine in the extract. Hence, column fraction 12 of the leaves was processed for HPLC analysis.

High Performance Liquid Chromatography analysis of fraction 12

Purification of the chemical in fraction 12 was carried out by chromatographic separation with Shimadzu's Prominence HPLC system, Japan. The HPLC chro- 
Table 4. TLC analysis of fractions obtained from column chromatography.

\begin{tabular}{|c|c|c|c|c|c|}
\hline Fraction No. & Retardation factor $\left(R_{f}\right)$ & Fraction No. & Retardation factor $\left(R_{f}\right)$ & Fraction No. & Retardation factor $\left(R_{f}\right)$ \\
\hline 1. & 0.22 & 8. & 0.14 & 15. & 0.12 \\
\hline 2. & 0.47 & 9. & 0.9 & 16. & 0.12 \\
\hline 3. & 0.91 & 10. & 0.9 & 17. & 0.33 \\
\hline 4. & 0.91 & 11. & 0.39 & 18. & 0.36 \\
\hline 5. & 0.9 & 12. & 0.27 & 19. & 0.11 \\
\hline 6. & 0.9 & 13. & 0.31 & 20. & 0.11 \\
\hline 7. & 0.12 & 14. & 0.35 & Berberine & 0.27 \\
\hline
\end{tabular}

Note: Twenty fractions obtained upon column chromatography were subjected for TLC along with berberine as a control molecule. The $R_{f}$ value for each fraction was calculated and compared to that of Rf value of berberine.

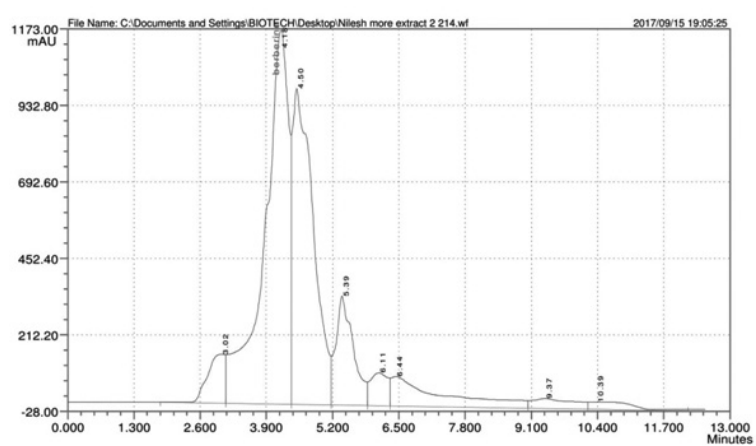

Figure 2. High Performance Liquid Chromatography for column fraction 12 of the leaf sample

matogram of the fraction 12 denotes three measurable peaks with retention time $4.14,4.5$ and 5.39 shown in Fig. 2. As expected, there was a major peak for pure berberine chloride with retention time 2.99 shown in Fig. 3. One minute difference was observed in the retention time for peak 2 of the extract and pure berberine chloride (Fig. 2 and Fig. 3). The second peak with retention time of 4.18 indicated the highest amount, hence it was purified as peak 2 and used for elucidation of the chemical formula.

\section{NMR analysisof the HPLC purified peak 2}

After HPLC analysis, which suggested the existence of beberine in the methanolic extracts of $A$. mexica$n a$, we decided to work on the structural differences of

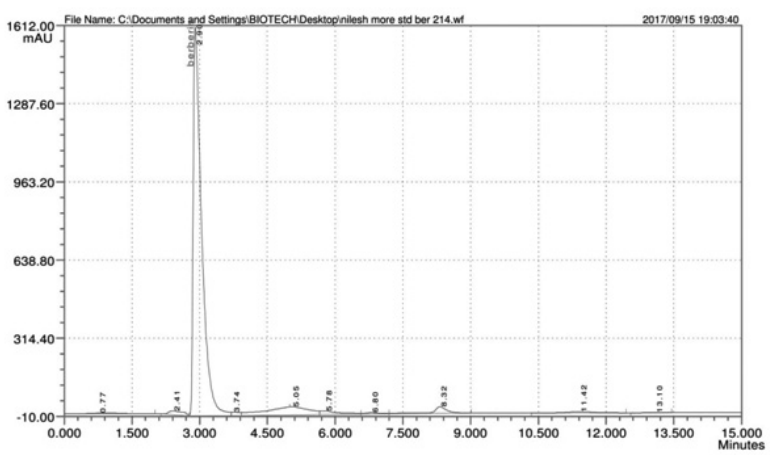

Figure 3. High Performance Liquid Chromatography for a standard berberine chloride sample the compound found within the HLPC peak 2 and the pure berberine chloride. The spectrogram obtained with 1H NMR (400 MHz, DMSO-d6) is shown in Fig. 4 of A. mexicana HPLC peak2. Analysis of the selected chemical shifts from $A$. mexicana leaves HPLC peak 2 include: $\delta 9.92(\mathrm{~s}, 1 \mathrm{H}), 8.96(\mathrm{~s}, 1 \mathrm{H}), 8.18(\mathrm{~d}, J=9.2 \mathrm{~Hz}, 1 \mathrm{H}), 7.99$ $(\mathrm{d}, \mathrm{J}=9.2, \mathrm{~Hz}, 1 \mathrm{H}), 7.76(\mathrm{~s}, 1 \mathrm{H}), 6.16(\mathrm{~s}, 2 \mathrm{H}), 4.96$ (t, $J=6.3 \mathrm{~Hz}, 2 \mathrm{H}), 4.08(\mathrm{~d}, \mathrm{~J}=13.2 \mathrm{~Hz}, 6 \mathrm{H}), 3.21$ (t, J=6.4 $\mathrm{Hz}, 2 \mathrm{H})$ for molecular formula $\left(\mathrm{C}_{20 \mathrm{H} 18} \mathrm{NO}_{4}\right)$. It is evident from $1 \mathrm{H}$ NMR spectrum shown in Figure 4 that two singlets at $\delta$ value 9.92 and 8.96 of $\mathrm{H}_{\mathrm{a}}$ are closer to $\mathrm{N}_{2}$, whereas $\mathrm{H}_{b}$ is away from $\mathrm{N}_{2}$ in the same ring. The $\mathrm{H}_{c}$ and $\mathrm{H}_{\mathrm{d}}$ aromatic protons are ortho coupled doublets at $\delta$ value 8.18 and $7.99(\mathrm{~J}=9.2 \mathrm{~Hz})$, another ring inferred the presence of isoquinoline moiety. The presence of another aromatic ring having four substituents is indicated by two singlets at $\delta$ value 7.76 and 7.06 of $H_{c}$ and $H_{4}$ respectively. Highly deshielded singlet at $\delta$ value $6.16^{\mathrm{l}}$ was assigned to a methylene group $\mathrm{CH}_{2}\left(\mathrm{C}_{\mathrm{g}}\right)$, which is situated between two oxygen atoms linked to the aromatic ring. In the spectrogram, two coupled triplets of $\mathrm{H}_{h}$ and $\mathrm{H}_{j}$ of dihydro-pyridine rings can be seen. The $\mathrm{H}_{j}$ appeared at $\delta$ value 3.21 and the spin - spin coupling constant $\mathrm{Jh}-\mathrm{j}$ in the range of $6.3-6.4 \mathrm{~Hz}$. The singlet that appeared at $\delta$ value 4.08 of 6 hydrogen is due to two methoxy groups. All chemical shift values of respective protons in the spectrum exactly matched with respective groups. The structure elucidated from 1HNMR spectrum and molecular mass from mass spectrum analysis through Mestrenova $\left(\mathrm{C}_{20} \mathrm{H}_{18} \mathrm{NO}_{4}\right)$ was exactly matched with the spectrum of berberine and structure of berberine with molecular formula which was obtained from the PubChem compound. The structure elucidated from the spectrogram, mestrenova and the PubChem was identical to berberine, shown in Fig. 5. This experiment confirmed the existence of berberine in the leaf methanolic extracts of $A$. mexicana.

\section{Functional demonstration of antibacterial potency for purified berberine}

Chang and coworkers (2003) carried out research on A. mexicana and suggested that berberine, ephendrine, hydrastine, canadine and palmatine are alkaloids present in this plant and they may be responsible for its antimicrobial activity. Hence, functional demonstration of antibacterial potency of berberine $\left(\mathrm{C}_{20} \mathrm{H}_{18} \mathrm{CINO}_{4}\right)$ from purified HPLC fraction was carried out. The HPLC purified peak 2 from the extract that originated from fraction 12, along with berberine purchased from Sigma Life Scienc- 


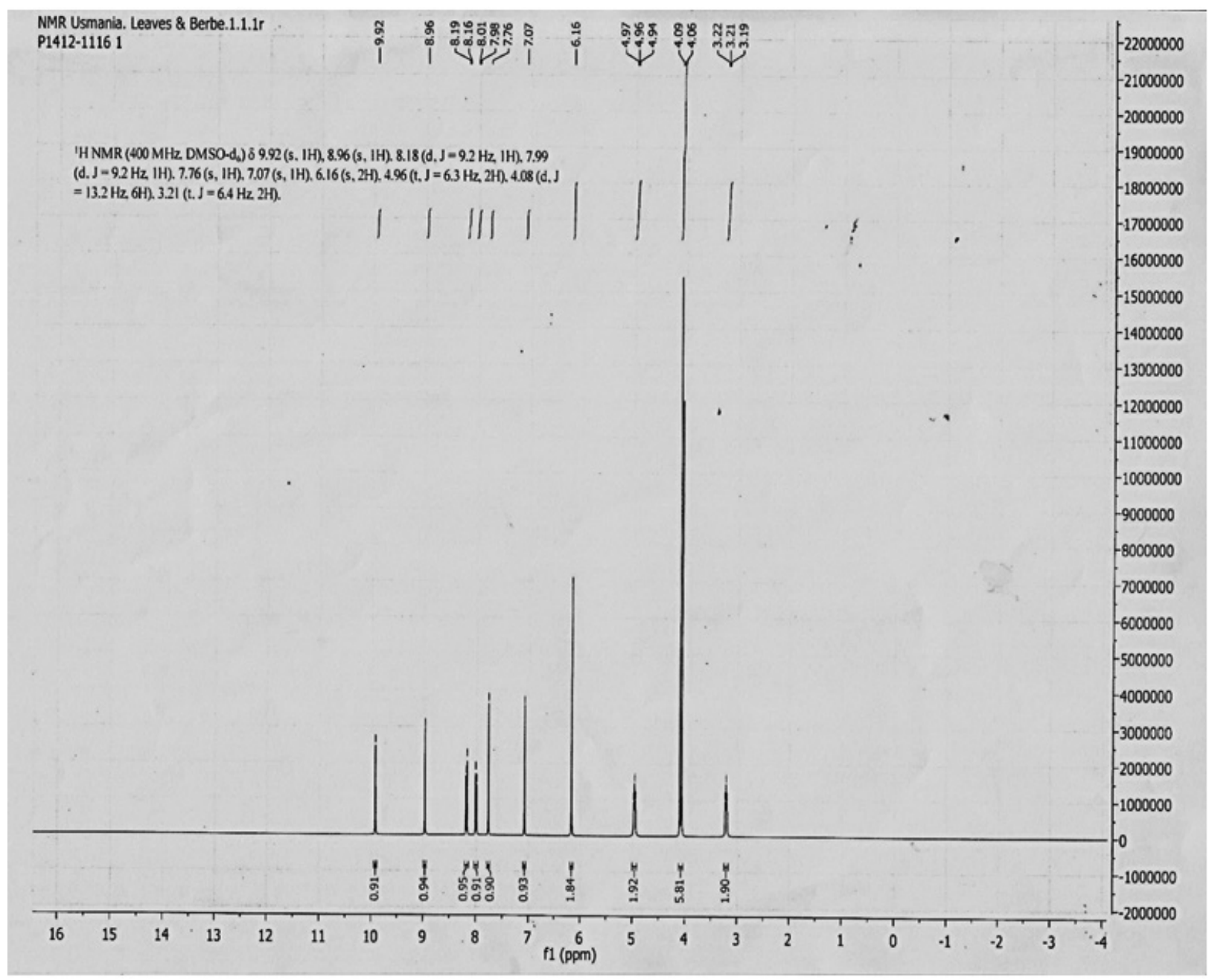

Figure 4. 1H NMR of HPLC Peak 2 of $A$. mexicana leaves

es and streptomycin were used to testify the ability to inhibit the growth of clinical isolates. Antibacterial potency was tested with the agar well diffusion assay described above. Results shown in Fig. 1B demonstrated that both, the HPLC peak 2 and berberine, exhibited identical activity. The black bar denotes activity of berberine, while the light gray bar denotes identical activity of the HPLC purified peak 2, and the empty bar shows similar antibacterial activity of streptomycin. It is evident from the results shown in Fig. $1 \mathrm{~A}$ and Fig. $1 \mathrm{~B}$ that the antibacterial potency seen with the leaf extracts of $A$. mexicana and HPLC purified fraction were equal. The NMR studies demonstrated that the chemical present in the HPLC

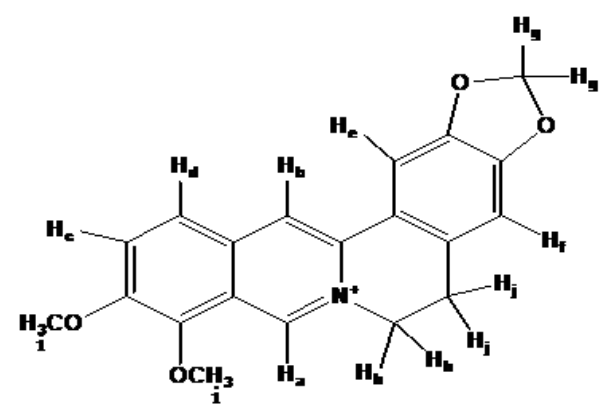

Figure 5. Chemical structure elucidated from 1H NMR spectrogram purified fraction is berberine and it would be suffice to say that the antibacterial potential demonstrated in the extract was likely due to berberine.

\section{DISCUSSION}

Previous studies (Chopra et al., 1986; Siddiqui et al., 2002; Osho \& Adentunji 2010; Rubio-Piña \& VázquezFlota, 2013) had demonstrated that oil extracts of A. mexicana, at various levels of concentration, exhibited inhibitory effects towards filamentous fungi and nonfilamentous fungus C. albicans, along with a few bacteria, such as Bacillus subtilis, Klebsiella pneumoniae, Staphylococcus aureus and Pseudomonas aeruginosa. With the use of agar well diffusion method evaluation of the antibacterial activity of crude extracts of aerial plant, root, stem, leaves and seed of $A$. mexicana against Bacillus subtilis, B. cerus, S. aureus, Streptococcus agalactae, Enterobacter faecalie, Clostridium botulinum, Clostridium perfringens - i.e.the Gram positive bacteria, and E. coli, E. coli 157, Salmonella typhimurium, Proteus mirabilis, Proteus vulgaris, Klebsiella pneumoniae, Pseudomonas aeruginosa - the Gram negative bacteria, was detected (Bhattacharjee et al., 2006; Rahman, 2009; Singh et al., 2009, Singh et al., 2009a; Osho \& Adentunji, 2010; Syam Prasad \& Dhanpal, 2010; Bhattacharjee et al., 2010; Alagesaboopati \& Kalaiselvi, 2012; Doss et al., 2012; Saranya, 2012). The present study aimed to spe- 
cifically demonstrate antibacterial activity and further characterize the active ingredient from the $A$. mexicana leaves. This is a first report documenting that $A$. mexicana leaf methanolic extract contains berberine. In addition to earlier reports, the study presented here also reiterates the antibacterial potentiality of $A$. mexicana leaf extract, either aqueous or methanolic, against clinical isolates of Bacillus cereus, Staphylococcus aureus, Pseudomonas aeruginosa and Escherichia coli (Fig. 1A). Furthermore, we have successfully purified the active ingredient, elucidated its structure (Fig. 5) and confirmed its potency in comparison with that of the extract, as well as a standard broad spectrum antibiotic (Fig. 1B).

The $A$. mexicana derived compounds could play an important role in the development of drugs to control several diseases caused by various bacterial strains, particularly pathogenic Pseudomonas aeruginosa (Sharma \& Nathawat, 1987; Sahu et al., 2012), and have an antiviral potential against HIV (Chang et al., 2003). In their studies, Chang and coworkers (2003) had shown that Protopines argemexicaines $\mathrm{A}$ and $\mathrm{B}$ obtained from $A$. mexicana exhibited a strong anti-HIV activity. The anti-HIV properties were ascribed to an alkaloid, 6-aetonyldihydrochelerythrine. The first medicinal application for $A$. mexicana has been reported in "the divine of farmers herb - root classic", Yinxi (2008). Earlier studies also indicated that the A. mexciana exhibit antifungal activity against filamentous and non-filamentous fungi (Siddiqui et al., 2002; Singh et al., 2009a; Osho \& Adentunji, 2010; Syam Prasad \& Dhanpal, 2010; More \& Kharat, 2016). Our studies identified that the active ingredient present in the methanolic extracts of $A$. mexicana leaves was able to inhibit growth of Gram positive and Gram negative clinical bacteria. The MIC obtained for both of these groups of bacteria was $800 \mathrm{mg} / \mathrm{mL}$. Previous reports have indicated that when various solvents, such as ethanol, methanol, acetone, hexane, chloroform and water are used, the MIC for the $A$. mexicana extracts remained within a broad range of $125 \mathrm{mg} / \mathrm{mL}$ to $5.0 \mathrm{mg} / \mathrm{mL}$ (Rahman, 2009; Singh et al., 2009; Osho \& Adentunji, 2010; Bhattacharjee et al., 2010; Alagesaboopathi \& Kalaiselvi, 2012; Doss et al., 2012). A plausible explanation for the vast variation seen in the MIC from $125 \mathrm{mg} / \mathrm{mL}$ up to $5.0 \mathrm{mg} /$ $\mathrm{mL}$ could be attributed to diverse solvents, choice of bacterium and its genetic make-up, along with the extract generation procedure. Earlier studies have indicated that $A$. mexicana is likely to contain benzylisoquinoline alkaloids, such asbenzophenanthridines, protoberberines (berberine), protopines, Protomexicine, mexitindehydrocorydalmine, jatrorrhizine, columbamine, dl-tetrahydrocoptisine and dihydrocoptisine (Sharma \& Nathawat, 1987; Singh et al., 2012; Rubio-Pina \& Vazquez-Flota, 2013; Gobato et al., 2015). Sequential purification and characterization of the $A$. mexicana leaf extract was carried out using column chromatography, thin layer chromatography, high performance liquid chromatography and $1 \mathrm{H}$ NMR. When the column fractions were compared for their $R_{f}$ values with berberine, it was found that fraction 12 did have an identical Rf with that of commercial berberine. The fraction was found to contain three peaks, out of which the second peak with a retention time of 4.1 was found to carry high concentration of the compound when compared to the other two peaks. Interestingly, the retention time for commercial berberine was 2.99. The delayed retention time for the major compound found in peak 2 might have been due to impurities that existed in fraction 12 when compared with commercial berberine purity. The HPLC purified peak 2 was then processed with $1 \mathrm{H}$ NMR. Interestingly, despite the differences obtained in their retention time, when analyzed with the Mestrenova software the peak 2 spectrogram exhibited $100 \%$ similarity and was found to have an identical chemical formula, i.e. $\mathrm{C}_{20} \mathrm{H}_{18} \mathrm{NO}_{4}$ (Fig. 4 and Fig. 5). In previous studies by Bhattacharjee and coworkers (2010), the authors had purified the active antibacterial agent in the most potent fraction with methanol, and found it was an alkaloid, N-demethyloxysanguinarine. The berberine that exhibited broad spectrum antibacterial potency has been known to cause reversal of epithelial-to-mesenchymal transition (Chu et al., 2014). As the metastasis, a common cause of death due to cancer, largely relies on epithelial-to-mesenchymal transition, inhibiting this transition results in both, reduced metastasis and angiogenesis (Chu et al., 2014). The methanolic and cold aqueous extracts made from $A$. mexicana leaves and stem were shown to exert cytotoxic effect on A549, $\mathrm{SiHa}$ and $\mathrm{KB}$ immortalized cell lines (More \& Kharat, 2016).

Functional characterization of antibacterial potency indicated that the compound purified from the $A$. mexicana leaf methanolic extract was berberine and exhibited comparable broad spectrum antibacterial activity, as depicted in Fig. $1 \mathrm{~B}$.

\section{Acknowledgement}

The spectrometric analysis by Mr. Palke D. G. from Rajashree Shahu Mahavidylaya, Latur and critical editing of the manuscript by Helen Marie Curry is gratefully acknowledged by the authors.

\section{Conflict of interesT}

Authors do not have any conflict of interest to declare.

\section{REFERENCES}

Abdelwahab SI, Abdul AB, Elhassan MM, Mohan S, Mariod AA (2010) Phenolic Content and antioxidant activities of Goniothalamus umbrosus extracts. Int J Nat Pro Pharm Sci 1: 1-6

Alagesaboopathi ?, Kalaiselvi ? (2012) Antimicrobial activities of the root, stem and leaf extracts of Argemone mexicana L. Int J Biosci 2: 61-68

Bhattacharjee I, Chattarjee SK, Chattarjee S, Chandra G (2006) Antibacterial potentiality of Argemone mexicana solvent extracts against some pathogenic bacteria. Mem I Oswaldo Cruz 101: 645-648

Boyanova L, Gregova G, Nikolov R, Derejian S, Lazarova E, Katsarov N, Mitov I, Krastev Z (2005) Activity of Bulgarian propolis against 94 Helicobacter pylori strains in vitro by agar-well diffusion, agar dilution and disc diffusion methods J Med Microbiol 54: 481-483

Cai YZ, Luo Q, Sun M, Corke H, (2004) Antioxidant activity and phenolic compounds of 112 traditional Chinese medicinal plants associated with anticancer. Life Sci 74: 2157-2184

Chang YC, Hsieh PW, Chang FR, Wu RR, Liaw CC, Lee KH, Wu YC (2003) Two new protopinesargemexicaines A and B and the anti HIV alkaloid 6-acetonyldihydrochelerythrine from Formosan $A$. mexicana. Planta Medica 69: 148-152

Chopra RN, Nayar SL, Chopra IC (1986) Glossary of Indian Medicinal Plants including the supplement: Council of Scientific and Industrial Research, New Delhi.

Chu SC, Yu CC, Hsu LS, Chen KS, Su MY, Chen PN (2014) Berberine reverses epithelial-to-mesenchymal transition and inhibits metastasis and tumor-induced angiogenesis in human cervical cancer cells. Mol Pharmacol 86: 609-623

Doss A, Mubarack HM, Vijayasanthi M, Venkataswamy R (2012) Invitro antibacterial activity of certain wild medicinal plants against bovine mastitis isolated contagious pathogens. Ass J Pharm Clin Res 5: 90-93

Gobato R, Fedrigo DFG, Gobato A (2015) Molecular geometry of alkaloids present in seeds of mexican prickly poppy. In Qunatitative Biology, Subject Other Quantitative Biology, pp 1-12. Cornell University Library. arXiv:1507.05042

Graz B, Wilcox ML, Diakite C, Falquet J, Dackuo F, Sidibe O, Giani S, Diallo D (2010) Argemone mexicana decoction versus artesunate- 
amodiaquine for the management of malaria in Mali: Poicy and Public Health Implications. Trans R Soc Trop Med Hyq 104: 33-41

Gupta R, Ingale NA, Kaur N, Yadav P, Ingle E, Charania Z (2015) Ayurveda in dentirsy - a Review. I Int Oral Health 7: 141-143

Kapoor G, Saigal S, Elongavan A (2017) Action and resistance mechanisms of antibiotics: A guide for clinicians. J Anaesthesiol Clin Pharmacol 33: 300-305

McGettigan P, Roderick P, Mahajan R, Kadam A, Pollock AM (2015) Use of Fixed Dose Combination (FDC) Drugs in India: Central Regulatory Approval and Sales of FDCs Containing Non-Steroidal Anti-Inflammatory Drugs (NSAIDs), Metformin, or Psychotropic Drugs. PLoS Medicine 12: 1-28

More NV, Kharat AS (2016) Antifungal and anticancer potentiality of Argemone mexicana L. Medicines 3: 28

Newman DJ, Cragg GM (2007) Natural products as sources of new drugs over the last 25 years. J Nat Prod 70: 461-477

Osho A, Afetunji T (2010) Antimicrobial activity of the essential oil of Argemone mexicana Linn. I Med Plant Res 4: 19-22.

Rahman MM, Alam MJ, Sharmin SA, Rahman MM, Rahman A, Alam MF (2009) In vitro antibacterial activity of Argemone mexicana L (Papaveraceae). CMU J Nat Sci 8: 77-84

Rajpal V (2005) Standardization of Botanicals, Testing \& Extraction Methods of Medicinal Herbs 2: 329-330. Eastern publishers: New Delhi.

Rosas-Pinon Y, Meiia A, Diaz-Ruiz G, Aguilar ML, Sanchez-Nieto S, Rivero-Cruz JF (2012) Ethanobotanical survey and antibacterial activity of plants used in the altiplane region of mexico for the treatment of oral cavity infections. J Ethanopharmacol 141: 860-865

Roux D, Pier GB, Skurnik D (2012) Magic bullets for the $21^{\text {st }}$ century: the reemergence of immunotherapy for multi- and pan-resistant microbes. J Antimicrob. Chemother 67: 2785-2787

Rubio-Piña J, Vázquez-Flota F (2013) Pharmaceutical Applications of the Benzylisoquinoline Alkaloids from Argemone mexicana L. Curr Topics Med Chem 13: 2200-2207

Sahu MC, Debata NK, Padhy RN (2012) Antibacterial activity of Argemonemexicana L. against multidrug resistant Pseudomonas aeruginosa, isolated from clinical samples. Asian Pac J Trop Biomed 2: S800-S807
Saranya MS, Arun T, Iyappan P (2012) In vitro antibacterial activity and preliminary phytochemical analysis of leaf extracts of Argemone mexicana L. - a medicinal plant. Int J Curr Pharm Res 4: 85-87

Schwenninger SM, Lacroix C, Truttmann S, Jans C, Spoerndli C, et al. (2008) Characterization of low-molecular-weight anti-yeast metabolites produced by a food-protective Lactobacillus-Propionibacterium coculture. J Food Protec 71: 2481-2487

Sharma V, Nathawat GS (1987) Allelopathic influence of Argemone mexicana L, on some plant crops. Curr Sci 56: 427-443

Shyam Prasad G, Dhanpal R (2010) Antibacterial and antifungal activity of methanolic extracts of Argemone mexicana leaves. Int J of Phytopharmacol 1: 64-67

Siddiqui IA, Shaukat SS, Khan GH, Zaki MJ (2002) Evaluation of Argemone mexicana for control of root-infecting fungi in potato. $J$ Phytopathol 150: 321-329

Silverstein RM, Bassler GC, Morrill TC (1980) In Spectrometric Identification of Organic Compounds. 4th edn, p 226. John Wiley and Sons

Singh A, Singh S, Singh S, Singh TD, Singh VP, Pandey VB, Singh UP (2009a) Fungal spore germination inhibition by alkaloid dehydrocorydalmine and oxyberberine. J Plant Prot Res 49: 287-289

Singh S, Pandey VN, Singh TD (2012) Alkaloids and flavonoids of Argemone mexicana. Nat Prod Res 26: 16-21

Singh SK, Pandey VD, Singh A, Singh C (2009) Antibacterial activity of seed extracts of Argemone mexicana L. on some pathogenic bacterial strains. Afr J Biotechnol 8: 7077-7081

Sorg RA, Lin L, van Doorn GS, Sorg M, Olson J, Nizet V, Veening JW (2016) Collective resistance in microbial communities by intracellular antibiotic deactivation. PLoSBiol 14: e2000631

Uddin SJ, Grice ID, Tiralongo E (2011) Cytotoxic effects of bangladeshi medicinal plant extracts. Evid Based Compl Alt Med 2011: 1-7. doi.org/10.1093/ecam/nep111

Washington JA, Sutter V L (1980) Dilution susceptibility test, Agar and macro broth dilution procedures. J Med Microbiol 10: 453-458

Yinxi T (2008) The divine of farmer's herb - root classic, category: book - medicine/traditional Chinese medicine. ISBN: 7533025296, 9787533025298, China 